\title{
O olhar sobre a natureza do Brasil: do deslumbramento à devastação
}

Solange de Aragão

Euler Sandeville Júnior ${ }^{2}$

DOI 10.20396/eha.vil4.3327

Introdução

Nas últimas décadas, alguns estudiosos têm se debruçado sobre a questão da devastação da floresta brasileira e da degradação do meio ambiente, resultantes do processo de derrubada de árvores, extração de minérios, queimadas para o plantio e para o pastoreio, durante o período colonial e à época do Império. Há estudos também voltados à questão da necessidade de preservação e recuperação da natureza a partir de textos elaborados ainda nos séculos XVIII e XIX, revelando uma consciência ambiental precursora à europeia e norte-americana, como se observa na obra Um sopro de destruição - pensamento político e crítica ambiental no Brasil escravista (1786-1888), de José Augusto de Pádua.

Dentro deste panorama bastante atual, pretende-se, neste artigo, tratar do olhar sobre a natureza do Brasil desde a época do descobrimento até o século XX, destacando-se a dicotomia desse olhar, que oscila entre o deslumbramento e a percepção das possibilidades de lucro advindas da exploração, e as mudanças constatadas ao longo do tempo a partir da leitura de documentos históricos, como a Carta, de Pero Vaz de Caminha e os diversos tratados sobre a terra do Brasil, de textos literários, como os romances de José de Alencar, nos quais se evidencia principalmente a transformação das paisagens do Rio de Janeiro, e de ensaios, como aqueles escritos por Paulo Prado e Gilberto Freyre. Interessa, portanto, o olhar, o modo como portugueses, brasileiros e estrangeiros consideraram a natureza do Brasil.

Olhares sobre a natureza

No primeiro documento sobre o Brasil, Pero Vaz de Caminha registra seu encantamento em

\footnotetext{
1 Arquiteta, Urbanista, Mestre e Doutora pela FAU-USP, com pós-doutorado em História do Brasil pela FFLCH-USP e pós-doutorado em História da Arquitetura pela FAU-USP. Professora Doutora de Arquitetura e Urbanismo da Universidade Nove de Julho, em São Paulo.

2 Professor Livre-Docente da Faculdade de Arquitetura e Urbanismo da Universidade de São Paulo.
} 
relação à terra avistada, de ponta a ponta, toda praia, com barreiras vermelhas e brancas, e a terra acima cheia de grandes arvoredos, com muitas águas, infinitas. Por outro lado, menciona não saber se havia nela ouro ou prata ou qualquer outra coisa de metal ou ferro, revelando desde o primeiro momento a dicotomia do olhar.

"Esta terra, Senhor, parece-me que, da ponta que mais contra o sul vimos, até a outra ponta que contra o norte vem, de que nós deste porto houvemos vista, será tamanha que haverá nela bem vinte ou vinte e cinco léguas de costa. Traz ao longo do mar em algumas partes grandes barreiras, umas vermelhas, e outras brancas; e a terra de cima toda chã e muito cheia de grandes arvoredos. De ponta a ponta é toda praia... muito chã e muito formosa. Pelo sertão nos pareceu, vista do mar, muito grande; porque a estender olhos, não podíamos ver senão terra e arvoredos terra que nos parecia muito extensa.

Até agora não pudemos saber se há ouro ou prata nela, ou outra coisa de metal, ou ferro; nem Iha vimos. Contudo a terra em si é de muito bons ares frescos e temperados [...]. Águas são muitas; infinitas. Em tal maneira é graciosa que, querendo-a aproveitar, dar-se -á nela tudo; por causa das águas que tem!”3

Trata-se da primeira visão das terras do Brasil a partir do mar. Uma visão limitada diante da real extensão da costa brasileira, mas que perscruta e constata a existência da floresta. Uma visão que se aproxima e observa a qualidade do solo, que tudo dá "por causa das águas que tem".

Quase um século depois, em 1587, Gabriel Soares de Sousa, em seu Tratado Descritivo do Brasil, após escrever longamente sobre os rios, sobre Salvador e sobre o Rio de Janeiro, já no final do texto, afirma que no sertão da Bahia havia esmeraldas de honesto tamanho e ouro e prata de tanta parte quanto se poderia imaginar. Assim, embora sua intenção inicial fosse "manifestar a grandeza, fertilidade e outras grandes partes que tem a Bahia de Todos os Santos e demais Estados do Brasil", Gabriel Soares de Sousa relega para as últimas linhas de seu Tratado informações sobre o ouro, a prata e as esmeraldas, que eram possivelmente as que mais atrairiam leitores. Essa organização textual por si só atribui importância significativa a esse outro olhar sobre o Brasil - um olhar que visa o lucro com as riquezas que o país possui não obstante as riquezas que o país produz.

No Tratado de Terra do Brasil (1576), de Pero de Magalhães Gândavo, difundem-se as notícias do ouro e da esmeralda — "umas pedras verdes que havia numa serra muitas léguas pela terra adentro" e "muito ouro, segundo as mostras e os sinais que acharam" — levando o autor a afirmar: “E se lá tornar gente apercebida como convém, com toda a provisão necessária, e levarem pessoas

3 CAMINHA, 1500. 
que disto conheçam, dizem que se descobrirão nesta terra grandes minas." ${ }^{4}$

E de fato foram descobertas grandes minas nesta terra nos séculos seguintes à elaboração do Tratado, especialmente no século XVIII, quando despontam cidades como Vila Rica, em Minas Gerais, e Cuiabá, no Mato Grosso, onde o ouro brotava nas ruas e nos quintais das residências.

Em 1618, Ambrósio Fernandes Brandão, escreve a obra Diálogos das Grandezas do Brasil, destacando as matas e os bosques naturais, "acompanhados de tão crescidos arvoredos", afirmando ainda que "destas semelhantes plantas há tantas e diversas castas que se embaraçam os olhos na contemplação delas". Há que se ressaltar também a mudança no olhar no que diz respeito ao lucro produzido pela terra, que se desloca do ouro e da prata para o pau-brasil:

Alviano: Não entendia que o pau-brasil era coisa de tanto rendimento para a fazenda de Sua Majestade, sem na sustentação dele gastar um só real, gastando muitos cruzados na Índia por adquirir as demais drogas.

Brandonio: Todo o Brasil rende para a fazenda de Sua Majestade sem nenhuma despesa, que é o que mais se deve estimar. ${ }^{5}$

Na obra A ferro e fogo - a história e a devastação da Mata Atlântica, Warren Dean apresenta uma estimativa da quantidade de pau-brasil extraída durante o período colonial: de cinco a doze mil toneladas por ano, resultando na derrubada de aproximadamente dois milhões de árvores durante o primeiro século do tráfico ${ }^{6}$, gerando de fato muito rendimento para a Metrópole.

Outra mudança no olhar aparece em Cultura e Opulência do Brasil (1711), de André João Antonil, que estabelece inclusive uma crítica às minas de ouro em contraposição à riqueza resultante da produção de cana-de-açúcar:

"AS TERRAS BOAS OU MÁS são o fundamento principal para ter um engenho real bom ou mau rendimento. As que chamam massapés, terras negras e fortes, são as mais excelentes para a planta da cana. [...]

FEITA A ESCOLHA da melhor terra para a cana, roça-se, queima-se e alimpa-se, tirando-Ihe tudo o que podia servir de embaraço. [...]

A necessidade obriga a vender barato e a queimar (como dizem) o açúcar fino [...]. Também a falta de navios é causa de se não dar por ele o que vale. Mas, o ter crescido tanto nestes anos o preço do cobre, ferro e pano, [...] e particularmente o valor dos escravos [...] é a principal causa de haver subido tanto o açúcar depois de haver moeda provincial e nacional e depois de descobertas as minas de ouro, que serviram para enriquecer a poucos e

4 GÂNDAVO, 1576.

5 BRANDÃO, 1618.

6 DEAN, 1996, p.64. 
para destruir a muitos, sendo as melhores minas do Brasil os canaviais e as malhadas, em que se planta o tabaco."7

Há nesse trecho uma descrição do processo de implantação dos engenhos de açúcar que faz menção às queimadas, a forma mais comumente adotada para limpeza dos terrenos antes do plantio que inevitavelmente resultava na devastação da área florestada.

A leitura da Carta de Pero Vaz de Caminha e dos Tratados subsequentes revela, portanto, a dualidade do olhar, que transitava entre a admiração e o deslumbramento e a visão das riquezas que a terra poderia oferecer; revela ainda a transformação desse olhar no que concerne ao símbolo e ao significado dessa riqueza: da possibilidade do ouro e da prata, ao pau-brasil, à cana-de-açúcar. Poderíamos completar na sequência: à efetivação da descoberta do ouro (no século XVIII), ao café (nos séculos XIX e XX), à indústria (no século XX).

No século XIX, alguns pintores viajantes vieram ao Brasil para retratar sua natureza, sua paisagem, suas cidades, seu povo, seus costumes, as espécies da flora e da fauna. Entre esses pintores viajantes, estava o alemão Rugendas, que em seu relato de viagem chega a afirmar que a floresta brasileira era tão complexa e tão rica em beleza e detalhes, que em vão tentaria um pintor retratá-la. Não obstante, uma das imagens que produz corresponde à representação da selva tropical brasileira. Mas esse pintor estava atento também ao processo de transformação da paisagem, registrando em suas gravuras a devastação de uma área florestada e as montanhas de Minas com um número expressivo de subtrações em suas encostas para extração do ouro. Que diversos estrangeiros viessem ao Brasil para registrar as suas riquezas e enviar esse registro para seus países de origem é indubitável, todavia em muitos casos, como nessas obras mencionadas, prevalece a sensibilidade do artista diante da beleza da natureza e seu assombro diante de sua destruição.

Já em meados do oitocentos, a natureza e seu processo de devastação chamariam a atenção de alguns fotógrafos, como Revert Klumb, que faria registros tanto das florestas e paisagens naturais, como da derrubada de árvores e das queimadas, tão comuns naquele momento. Mais uma vez, o artista poderia ter optado por fotografar apenas as áreas florestadas e as paisagens naturais, mas de alguma forma a devastação da natureza o sensibilizou, levando ao registro da transformação da paisagem brasileira para obtenção do lucro.

Não eram apenas os estrangeiros que sentiam a necessidade de fazer esse registro. Alguns escritores do período retrataram as mudanças da paisagem em seus romances, como tantas vezes 
o fez José de Alencar:

"Tomando para o lado da cascatinha, que as chuvas dos últimos dias tinham enriquecido, lembrou-se o moço de subir até a Floresta, um dos mais lindos sítios da Tijuca. O nome pomposo do lugar não é por ora mais do que uma promessa; quando porém crescerem as mudas de árvores de lei, que a paciência e inteligente esforço do engenheiro Archer têm alinhado aos milhares pelas encostas, uma selva frondosa cobrirá o largo dorso da montanha, onde nascem os ricos mananciais. Viva a imagem da loucura humana! Refazer à custa de anos, trabalho e dispêndio de grande cabedal, o que destruiu em alguns dias pela cobiça de um lucro insignificante! Aquelas encostas secas e nuas, que uma plantação laboriosa vai cobrindo de plantas emprestadas, se vestiam outrora de matas virgens, de árvores seculares, cujos esqueletos carcomidos às vezes se encontram ainda escondidos nalguma profunda grota. Veio o homem civilizado e abateu os troncos gigantes para fazer carvão; agora, que precisa da sombra para obter água, arroja-se a inventar uma selva, como se fosse um palácio." ${ }^{8}$

A floresta da Tijuca foi devastada para o plantio do café, o que contribuiu para a falta de água na cidade, levando, consequentemente, à necessidade de reflorestamento9. Infelizmente, no que diz respeito às florestas do Brasil, esse olhar do escritor oitocentista permanece bastante atual uma vez que nossas florestas continuam sendo destruídas em alguns dias "pela cobiça de um lucro insignificante".

No século XX, essa consciência dos danos ambientais resultantes da busca desenfreada do lucro aparece tanto nos textos literários, especialmente em crônicas e poemas de escritores como Cecília Meirelles e Carlos Drummond de Andrade, como nos ensaios produzidos por intelectuais como Gilberto Freyre. Uma das descrições mais belas das florestas brasileiras, em particular da Floresta Amazônica e da Mata Atlântica, aparece na obra Retrato do Brasil, de Paulo Prado. É interessante observar que ainda que o literato se posicione claramente a favor das áreas florestadas, ele acaba por evidenciar o valor das espécies arbóreas:

"Pela costa do Atlântico a mata, aproveitando o acidentado do solo e a umidade condensadora dos ventos gerais de sueste, excede em beleza e pujança à própria floresta equatorial. [...] As madeiras preciosas, pelo refinado da qualidade e pela multiplicação das espécies, são superiores às da Hiléia [...]. É a mata do pau-brasil que deu nome à terra [...]."10

As madeiras da Mata Atlântica são de qualidade refinada e de várias espécies — madeiras

\footnotetext{
8 ALENCAR, 1872.

9 FRANCO, 2019.

10 PRADO, 1997, p.123.
} 
preciosas sendo seu valor produzido pela derrubada das áreas florestadas e não pela manutenção e preservação de sua beleza e pujança. Difícil desvencilhar-se desse olhar - mesmo para os admiradores da floresta.

Gilberto Freyre, por sua vez, demonstra como a devastação das áreas florestadas para o plantio da cana-de-açúcar no Nordeste durante séculos resultou nas secas daquela região.

"O canavial hoje tão nosso, tão da paisagem desta sub-região do Nordeste, que um tanto ironicamente se chama "a Zona da Mata", entrou aqui como um conquistador em terra inimiga: matando as árvores, secando o mato, afugentando e destruindo os animais e até os índios, querendo para si toda a força da terra. [...]

Já os traficantes franceses tinham derrubado muito pau-brasil. Os primeiros portugueses continuaram a derrubar a madeira de tinta com o auxílio dos índios. [...]

Mas foi com o começo da exploração agrícola que o arvoredo mais nobre e mais grosso da terra foi sendo destruído, não aos poucos, mas em grandes massas [...]."11

Essa última visão do sociólogo, que afirma que o arvoredo não foi destruído aos poucos mas em grande quantidade, ratifica a visão do escritor oitocentista, José de Alencar.

No âmbito da Literatura do século XX, dos inúmeros poemas que surgiram em defesa das florestas, pode-se destacar um de Carlos Drummond de Andrade, que evidencia os motivos por vezes tão fúteis que levaram à derrubada das árvores e à extinção de algumas espécies, como aquela descoberta por George Gardner um século antes.

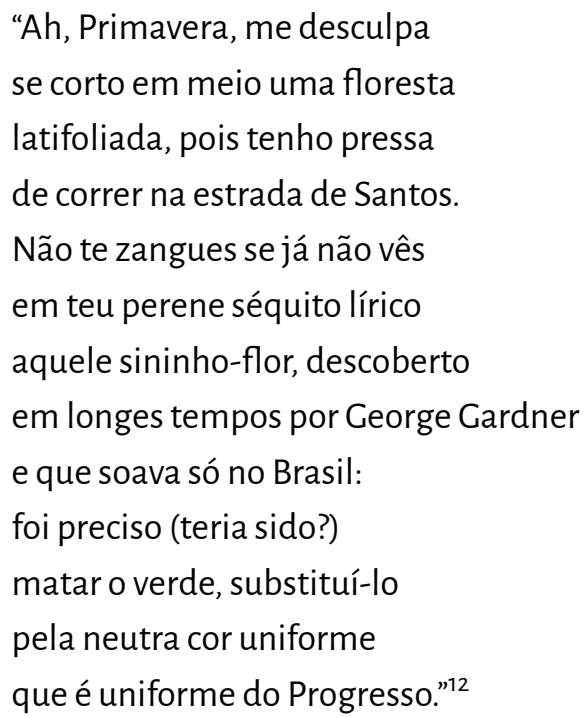

A floresta é derrubada para o plantio (da cana-de-açúcar, do café), para o pastoreio, para o 
aproveitamento da madeira das árvores, para a construção de estradas, de hidrelétricas e de tudo mais que o progresso solicita. A questão é que o progresso não reconhece a riqueza da preservação da floresta. Nem o progresso, nem a visão do lucro, que tão facilmente se opõe ao olhar do deslumbramento.

\section{Conclusão}

Na Literatura, como na arte de um modo geral, e mesmo nos textos informativos, como artigos de jornal, aparece a dicotomia do olhar sobre a natureza do Brasil. Embora muitas vezes se reconheça a grandeza e a pujança dessa natureza, não raro se sobrepõe a essa visão o olhar que anseia pelo lucro apesar da devastação que este traz como consequência. E esse lucro não se divide, não se compartilha com a sociedade de um modo geral a quem efetivamente pertencem as riquezas naturais do país. Ao contrário, concentra-se nas mãos de poucos, como se as florestas, as montanhas, o subsolo não devessem trazer benefícios a todos os cidadãos. É provável, ainda, que a maioria fosse (e ainda seja) favorável à preservação de nossa natureza e não a seu esvaimento. Questão de visão. Questão do olhar sobre a natureza do Brasil. 


\section{Referências Bibliográficas}

ALENCAR, José de. Sonhos D' Ouro [1872]. Texto proveniente da Fundação Biblioteca Nacional (http://www.bn.br). Disponível em: http://www.dominiopublico.gov.br. Acesso em 2019.

ANDRADE, Carlos Drummond de. Discurso de primavera e algumas sombras. Rio de Janeiro: Record, 1994.

ANTONIL, André João. Cultura e Opulência do Brasil [1711]. 3.ed. Belo Horizonte: Itatiaia: Edusp, 1982. Texto proveniente da Biblioteca Virtual do Estudante Brasileiro (http://www.bibvirt.futuro.usp.br). Disponível em: http://www.dominiopublico.gov.br. Acesso em 2019.

BRANDÃO, Ambrósio Fernandes. Diálogos das grandezas do Brasil [1618]. Salvador: Progresso, 1956. Texto proveniente da Biblioteca Virtual do Estudante Brasileiro (http://www.bibvirt.futuro.usp.br). Disponível em: http://www.dominiopublico.gov.br. Acesso em 2019.

CAMINHA, Pero Vaz de. Carta a El Rei D. Manuel. Ilha de Vera Cruz, maio de 1500. Texto proveniente da Biblioteca Virtual do Estudante Brasileiro (http://www.bibvirt.futuro.usp.br). Disponível em: http://www.dominiopublico.gov.br. Acesso em 2019.

DEAN, Warren. A ferro e fogo a história e a devastação da Mata Atlântica. São Paulo: Companhia das Letras, 1996.

FRANCO, Luíza. O tempo em que o Rio de Janeiro secou após destruir floresta por café . BBC News Brasil, 01.09.2019. Disponivel em: https://www.bbc.com/portuguese/geral-49530574. Acesso em: 2019.

FREYRE, Gilberto. Nordeste. Rio de Janeiro: Record, 1989.

GÂNDAVO, Pero de Magalhães. Tratado de Terra do Brasil [1576]. Texto proveniente da Fundação Biblioteca Nacional (http://www.bn.br). Disponível em: http://www.dominiopublico.gov.br. Acesso em 2019.

PÁDUA, José Augusto de. Um sopro de destruição pensamento político e crítica ambiental no Brasil escravista (1786-1888). 2.ed. Rio de Janeiro: Jorge Zahar, 2004.

PRADO, Paulo. Retrato do Brasil. São Paulo: Companhia das Letras, 1997.

SOUSA, Gabriel Soares de. Tratado descritivo do Brasil em 1587. Texto proveniente do Ministério da Educação. Disponível em: http://www.dominiopublico.gov.br. Acesso em 2011. 